\title{
Long term results of Draf type III (modified endoscopic Lothrop) frontal sinus drainage procedure in 122 patients: a single centre experience*
}

\author{
C. Georgalas, F. Hansen, W.M.J.Videler, W.J. Fokkens
}

Department of Otorhinolaryngology, Academic Medical Center (AMC), Amsterdam, the Netherlands

\begin{abstract}
SUMMARY
Objectives: To assess the effectiveness and factors associated with restenosis after Draf type III (Endoscopic Modified Lothrop) frontal sinus drainage procedure. Design: Retrospective analysis of prospectively collected data. Patients: A hundred and twenty two consecutive patients undergoing Draf III procedure for recalcitrant chronic frontal rhinosinusitis (CRS) (71\%), frontal sinus mucocoele (15\%), benign frontal sinus tumours (9\%) and cystic fibrosis with severe CRS (5\%) were followed up for an average of 33 months. Outcome measures: Symptom burden (Visual Analogue Scale and Rhinosinusitis Outcome Measure), patency of neo-ostium and revision surgery. Results: At the end of follow up, ninety percent of patients had a patent neo-ostium, while $88 \%$ were either clinically better or completely asymptomatic. Thirty-nine patients required endoscopic revision surgery and 9 eventually underwent frontal sinus obliteration. Sixty percent of revision operations were performed during the first two years. RSOM showed a significant improvement in both general and nasal symptoms while on a VAS, headache improved significantly. The only factor weakly associated with re-stenosis was the presence of allergy. There were no major complications during any of the procedures. Conclusion: Draf III Procedure is safe and effective for patients who have failed conventional frontal sinus procedures and a valid alternative to frontal sinus obliteration. Although the revision rate may appear to be quite significant, it can often be performed as an outpatient procedure and needs to be balanced against the reduced morbidity and the ease of follow-up.
\end{abstract}

Keywords: frontal sinus, chronic rhinosinusitis, cystic fibrosis, osteoma, inverted papilloma, endoscopic sinus surgery, endoscopic Lothrop procedure, Draf 3 procedure, medial frontal sinus drainage procedure, revision surgery

\section{INTRODUCTION}

The surgical management of recalcitrant frontal sinus disease remains one of the biggest challenges in otolaryngology: before the endoscope era, endonasal approaches to the frontal ostia tended to have rather poor results while frontal sinus obliteration was the gold standard for patients with recalcitrant frontal sinus disease ${ }^{(1)}$. The advent of the endoscope and increased experience with its use led many to challenge this assumption, and in 1981, a new radical approach was developed by Professor Wolfgang Draf's group in Fulda (2): the endoscopic removal of the frontal beak, the floor of both frontal sinuses, the intersinus frontal septum and the adjacent part of the nasal septum, thus creating the biggest possible common drainage pathway. Although technically difficult, this approach gradually gained in popularity. However, it is a procedure aimed at the small group of patients with recalcitrant severe frontal sinusitis; hence, by definition most series described tend to be rather small. We present in this paper the largest single centre series of Draf III (endonasal modified Lothrop) procedures from the Academic Medical Centre, in Amsterdam, the Netherlands, aiming to assess its risks and benefits as well as its long-term clinical efficacy.

\section{PATIENTS AND METHODS \\ Patients}

This is a retrospective case study of all patients undergoing a Draf III procedure in our institution, from January 2001 to September 2009. Only patients with a follow up greater or equal to 6 months were included. Indications for surgery, demographic patient data, medical history including smoking, allergy, asthma or Sampter's triad /ASA triad) and surgical history was recorded. All patients underwent preoperative spiral computed tomography (CT) scans, reconstructed in axial, coronal and sagittal planes, which were then scored according to 
Lund Mackay radiological grading system ${ }^{(3)}$. On sagittal view the anteroposterior distance between the most anterior part of the bony nasal beak and the anterior skull base was measured at the level of the septum (maximal anteroposterior frontal sinus outflow tract diameter). On the axial view the maximal lateral diameter (LR) of the potential frontal outflow tract was measured in the same way (orbit to orbit). The endoscopic appearance of the neo-ostium at the most recent outpatient follow-up was graded as open, partly open or closed. Clinical outcomes were graded on the basis of the patient's main symptom as asymptomatic, improved, same/worse while 31 patients completed validated patient outcome measures (Rhinosinusitis Outcome Measure - RSOM $31{ }^{(4)}$ and Visual Analogue Scale for headache and facial pain - VAS).

\section{Statistics}

Statistical analysis was performed with PASW 18 for Mac. Pearson's Chi square and Fisher's exact test were used for comparing categorical variables, while comparisons between groups were performed using unpaired $t$ test for normally distributed variables and Wilcoxon rank test for non parametric variables, as required. The level of significance was set at 0.05 for double - sided comparisons while Bonferroni correction was used for all multiple comparisons.

\section{Indications and patient selection}

In the Academic Medical Centre, a tertiary referral centre, Draf III is reserved for symptomatic patients with recalcitrant chronic frontal rhinosinusitis who have failed maximum medical therapy as well as complete ethmoidectomies and functional endoscopic frontal sinus procedures and/or external frontal sinus drainage and patients with mucocoeles or tumours in the frontal sinus accessible endonasally. A less than $1 \mathrm{~cm}$ anteroposterior distance (AP) between the anterior nasal beak and the skull base as well as frontal sinus tumours originating extreme laterally of the orbit are considered relative contraindications.

\section{Surgical Technique}

All primary procedures were performed under general anaesthesia and, in most cases, using image navigation (LandmarX, Medtronic Xomed, Jacksonville, FL, USA). Revision surgery, when it included removal of polyps and/or granulation tissue without any bone drilling, was often performed under local anaesthetic, as an outpatient procedure. All patients received intraoperative coverage with wide spectrum antibiotics. Purpose-made cotton buds soaked in 1:1000 adrenaline and crystalline cocaine powder (total of $200 \mathrm{mg}$ ) were applied under direct vision to the area of the sphenopalatine, anterior ethmoid and greater palatine foraminae. A 30-degree endoscope was used throughout the procedure and, very rarely also a 45-degree endoscope. A complete anterior and posterior ethmoidectomy was performed, including all ethmoid cells, as ethmoid cell remnants can compromise the operation's success, both by limiting the frontal sinus outflow path as well as by acting as a nidus of persisting inflammation. A Draf IIa (simple frontal sinusotomy) was performed prefer- ably on both sides but, if impossible (for example because of blocking bone), at least on one side. An incision through the anterosuperior septum was then made with a 15 blade or with a monopolar cutting needle diathermy, starting at the level of the anterior rim of the frontal ostium and advancing 2 centimetres inferiorly and anteriorly. The mucosa from that part of the septum was then removed with a shaver and the septal cartilage with a cutting blakesley and/or scissors. The opening in the septum thus created was wide enough to visualise both frontal recesses from either nostril, but did not exceed more posteriorly than the first olfactory fibres. The anterior part of the middle turbinate was trimmed parallel to the septal ostium; sometimes, especially in cases with severe polyposis, the entire middle turbinate was removed. With a 40 - or 60 -degree shaver the soft tissue and mucosa between the two frontal ostia was then removed exposing the bone of the nasal beak and anterior frontal plate. Using a 40-degree cutting finesse burr, the rim of the anterior frontal plate was subsequently drilled in a rolling, smooth, anteromedial direction, keeping in mind that the skull base extends anteriorly in the midline. The drilling was continued superiorly, removing the intersinus septum as high as possible, and anteriorly, up to (almost) the skin, aiming to create the largest possible, smooth- edged common outflow pathway, defined by the lacrimal bones laterally, the anterior skull base posteriorly and the nasal skin anteriorly. We aim to preserve a thin (less than $0.7 \mathrm{~cm}$ ) bone layer at the skin side to prevent skin collapsing in the neo-ostium. We also aim to preserve as much of the ostium mucosa laterally and posteriorly as possible, while also avoiding drilling the posterior wall of the frontal sinus, although the anterior projection of the anterior skull base in the midline usually requires some very careful drilling after identification of the first olfactory nerve. At the end of the procedure no drains were used. Instead, we leave an antibiotic- and steroid-impregnated paraffin gauze in the neo-ostium, which is removed at the outpatient clinic after 10 days.

\section{Postoperative management}

Patients were discharged the day after the operation and were reviewed in the outpatient clinic after a week. At that outpatient visit, the paraffin gauze was removed endoscopically from the neo-ostium. Subsequently the patients were advised to rinse their nose with saline and use steroid nasal drops. Outpatient appointments for gentle debridement of the neo-ostium and removal of clots and crusts were made after one, then two weeks and subsequently every two weeks until healing was complete. In case of polyps growing into the neo-ostium, steroid and antibiotic cream was applied under endoscopic guidance in the outpatient clinic and if necessary patients received 14 days of oral prednisone and/or longer term antibiotics. Examples of patients are included in Figures 1a, 1b and 1c and 2a, 2b and 2c.

\section{RESULTS}

Patient characteristics

A hundred and twenty two patients were included in this study. Their mean age was 47 (range 11 to 78 years) and the female to male ratio $1: 1.18$. The indications for surgery included recal- 
Figure 1. (A, B) Preoperative scans of a 55-year-old patient with 6 previous FESS procedures and 2 external frontal sinus drainage procedures for recurrent frontal sinusitis. (C) Postoperative endoscopic view of the frontal sinus, 28 months postoperatively - patient remains asymptomatic

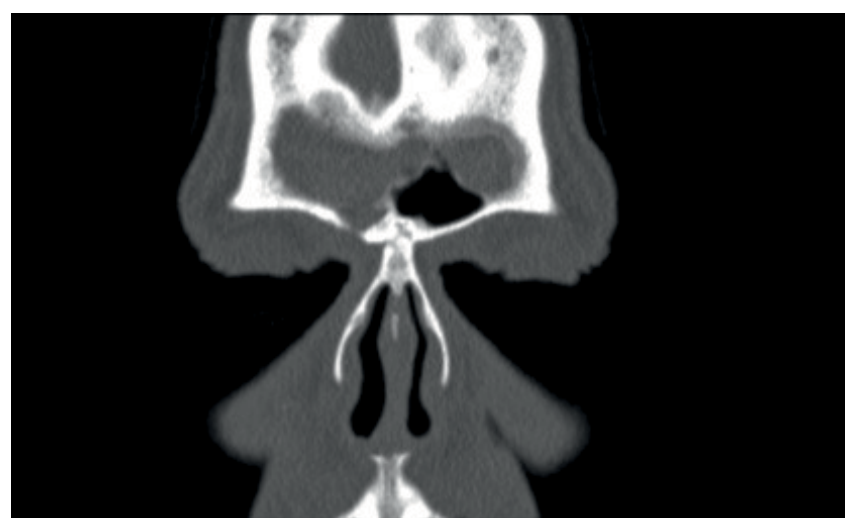

A
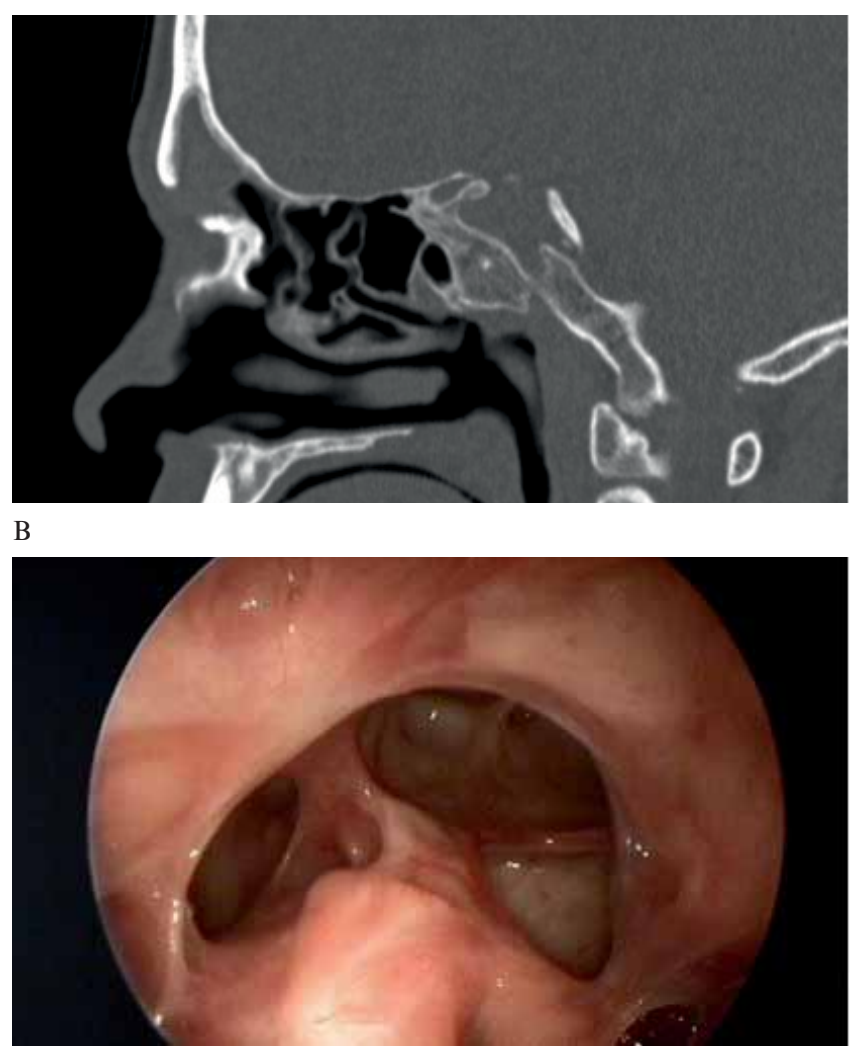

C

citrant chronic frontal sinusitis in eighty six $(70 \%)$ patients (52\% CRS with nasal polyps, $19 \%$ CRS without NP), while 19 patients $(16 \%)$ had mucocoeles of the frontal sinuses, eroding into the orbit or the anterior skull base, 6 patients $(5 \%)$ had cystic fibrosis and the same number had osteomata of the frontal sinus while 5 patients $(4 \%)$ had extensive inverted papillomata involving the frontal sinus (Table1). The vast majority (117/122) of patients (including all CRS patients) had had previous sinus surgery, with a mean of 3.4 procedures (range 0 to 24$)$. Sixty-three patients ( $52 \%$ ) had previous endoscopic surgery in the frontal sinus and $22(18 \%)$ had external frontal sinus procedures. Twenty seven percent of patients had skin-prick
Figure 2. (A, B) Recurrent frontal mucocele, after Draf 2a procedure. (C) Endoscopic view of neo-ostium 14 months postoperatively.

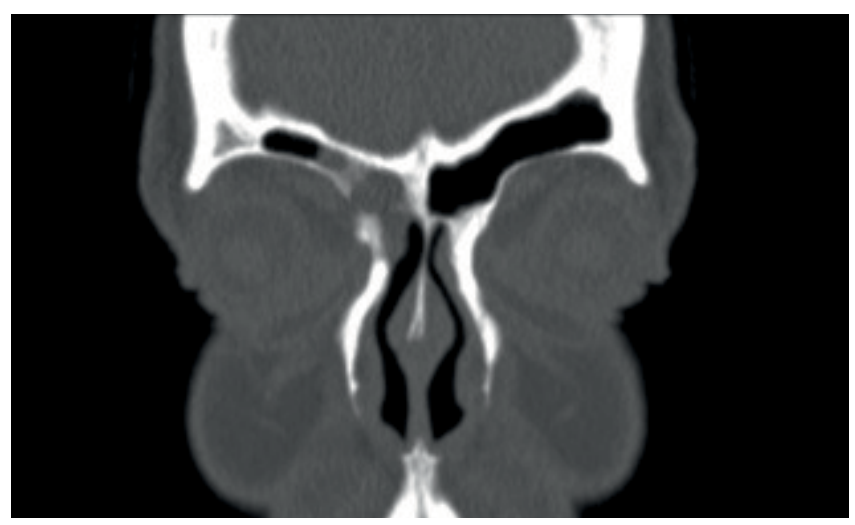

A

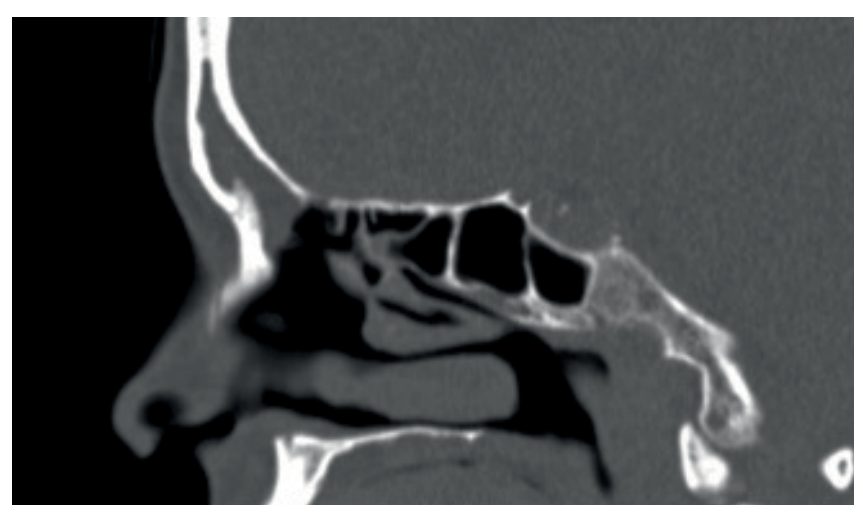

B

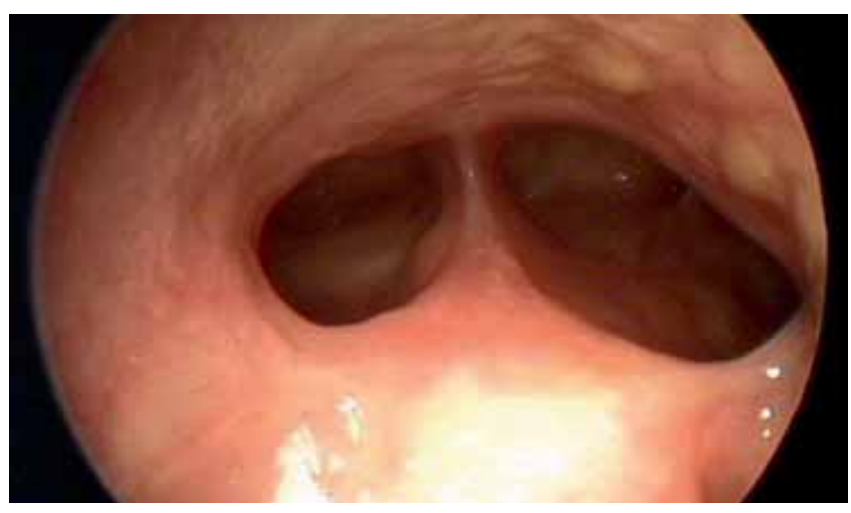

C

test-confirmed allergy and 39 percent had asthma, while 13 percent had aspirin-sensitive asthma and nasal polyps (ASA triad). Their mean follow up was 33 months, (range: 6 to 90 months). Their mean preoperative Lund Mackay radiological score was 13.5 (range 1 to 24) and mean anteroposterior distance between anterior skull base and the anterior part of the nasal bone measured at midline was $13.5 \mathrm{~mm}$ (range 9 to 20) while mean lateral diameter of the potential frontal sinus outflow tract was 25.3 (range 17 to $33 \mathrm{~mm}$ ).

\section{Clinical outcomes}

At the end of follow up, $80(66 \%)$ patients were asymptomatic, 
Figure 3. RSOM 31 scores before and after surgery $(n=33)$.

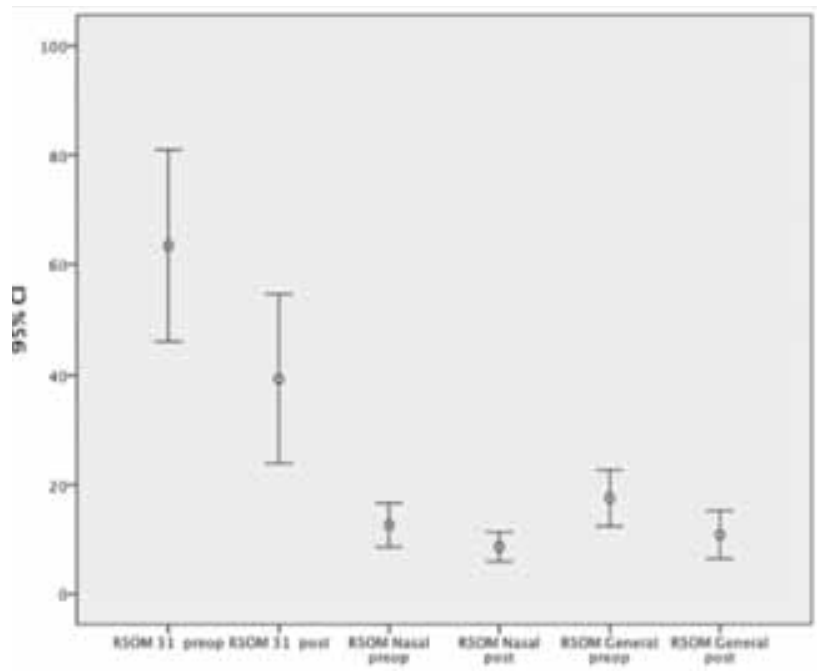

$27(22 \%)$ had reduced symptoms while $15(12 \%)$ were the same or worse than before the surgery. Thirty-three patients underwent preoperative and postoperative evaluation with Visual Analogue Scales: In these patients, mean VAS score for headache decreased from 57.7 preoperatively to 40.7 postoperatively $(p=0.02$, paired t-test). A decrease was also seen in the VAS score for facial pain: 61.1 to 42.1 ( $\mathrm{p}=0.01$, paired $\mathrm{t}$-test). Total RSOM -31 scores changed from 63.4 preoperatively to 39.3 postoperatively ( $p=0.015$, paired t-test). The subscales for nasal and general symptoms decreased from 15.3 to $11.2(\mathrm{p}=$ 0.017 ) and 19.3 to 12.3 ( $\mathrm{p}<0.001$, paired t-test), respectively (Figure 3).

\section{Endoscopic outcomes}

At last follow up, frontal sinus neo-ostium was fully open in 86 (76.1\%) patients, partly open in $16(13.9 \%)$ patients and closed in $11(9.7 \%)$ patients, while it could not be assessed in 9 patients who underwent frontal sinus obliteration.

\section{Correlation between endoscopic outcomes and symptoms}

It is interesting to note that the frontal sinus neo-ostium was closed only in 1 out of the 11 patients who did not improve - while 5 had completely and 4 partly open outflow tracts at the last follow up. Conversely, we noted that 4 out of the 11 patients with obstructed ostia at last follow up were clinically asymptomatic.

\section{Revision surgery}

Thirty-nine patients $(32 \%)$ underwent revision surgery, (thirty-eight revision Draf 3 and one obliteration for Chronic Rhinosinusitis complicated by traumatic frontal sinus fracture) at an average of 14.6 months after the first surgery. After the first revision (39 patients), 21 (54\%) had partly or completely open neo-ostium at the last follow up. However, 18 of these 39 patients underwent a second revision, which took the form of a frontal sinus obliteration in 8 patients and revision Draf 3 in 10. The ostium remained patent in 9 of these 10 patients $(90 \%)$ (Figure 4) (Flowchart 1).
Figure 4. Revision surgery over time.

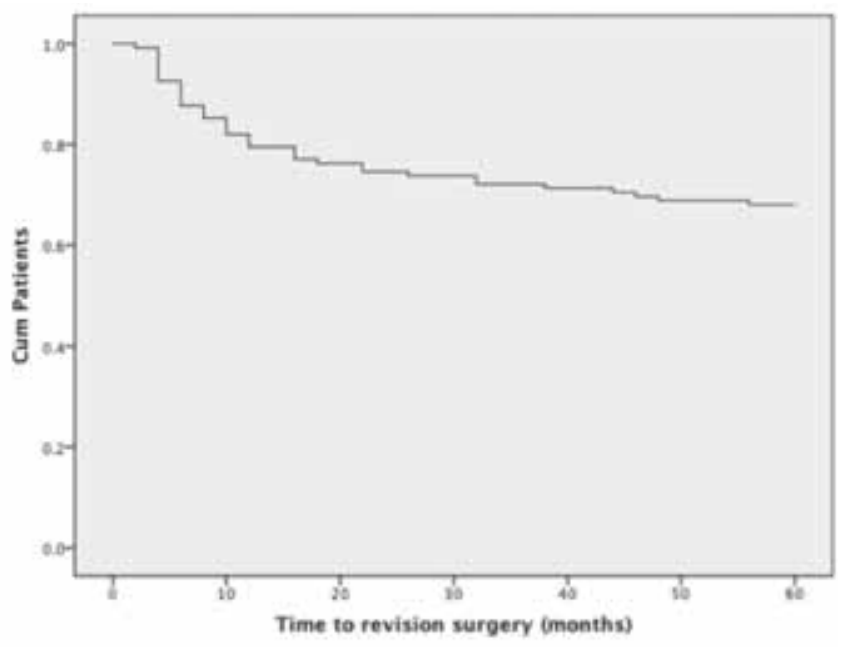

Predictive factors for restenosis

There did not appear to be a correlation between age, symptom duration, number of previous (frontal) sinus procedures or anatomical measurements of frontal sinus outflow tract and neo-ostium re-stenosis. However, there was evidence of a weak association between allergy and frontal sinus outflow obstruction: Only 5 out of $81(6 \%)$ patients without allergy had a closed ostium at last follow up as opposed to 6 out of $31(19 \%)$ of patients with allergy $(\mathrm{p}=0.04$, Chi-square test). Similarly, patients with asthma had higher rates of neo-ostium obstruction (7/44 versus $4 / 68$, or 15.9 versus $5.9 \%, p=0.08$, NS, Pearson chi-square test). A similar - but not significant - trend was observed in patients with ASA triad $(20.1 \%$ closure rate versus $8.2 \%$ in non ASA patients) (Table 1). Regarding the indication for surgery, although the dataset was not big enough to get some clear results, it appeared that the risk of re-stenosis was highest in patients with Cystic Fibrosis, whereby it closed in 2 out of 5 patients, while in patients with CRS without polyps only one out of 22 patients had a closed ostium at last follow-up (Table 2). We did not have any significant orbital or cranial complications in our group.

\section{DISCUSSION}

A generally accepted dictum about the frontal recess is to preserve its mucosa or pay the consequences - in the form of difficult to treat, recalcitrant frontal sinusitis and mucocoeles. Hence, an operation that produces extensive mucosal and bony injury by introducing an aggressive cutting instrument such as a rotating drill in that most sensitive area seems counterintuitive. However, the success and popularity of the Draf III or Endoscopic Modified Lothrop procedure is based on the fact that, for patients with severely diseased frontal sinus mucosa, it is a valid alternative to an obliteration procedure: It does not require an external incision, has reduced morbidity, hospitalisation and costs and last but not least produces an open cavity that is easier to assess and follow up in the clinic without the need for serial CT scans or MRIs. Technically, one 'gets away" with the use of the drill by avoiding circumferential mucosal trauma and by preserving the posterior and lateral frontal 
recess, and creating a drainage pathway so large that, by its sheer size, can countenance the inevitable postsurgical soft tissue scarring and granulation tissue formation.

The obliteration procedure is well established, being in use for more than 40 years, and is technically accessible to most otolaryngologists. However, it has been associated with up to $9.4 \%$ mucocoele formation rates within 2 years ${ }^{(5)}$ as well prolonged hospitalisation, supraorbital numbness, impaired cosmesis, the need for an abdominal incision for fat harvesting and (rarely) in case of intracranial entry, potential severe complications. On the other hand, the Draf III procedure has not gone through the test of time in the same way, is more technically challenging while it has also the risk of severe complications, such as CSF leak, orbital damage and major bleeding.

In our hospital we have been using the Draf III procedure since 2001 for either extensive frontal sinus mucocoeles with posterior frontal plate or orbital extension and for severely scarred frontal recesses after multiple surgeries. Our therapeutic ladder in recalcitrant frontal sinusitis initially includes one or more attempts to open the frontal recess in the conventional way (Draf 2a) and only if that is repeatedly unsuccessful, proceed to a Draf III. In a much smaller number of patients, with chronic frontal sinusitis and ASA triad, Cystic Fibrosis or multiple mucocoeles and extensive nasal polyposis, Draf III is used as a primary frontal procedure, while in a handful of cases, it is used either for access for removal of benign tumours (osteomata or inverted papillomata) of the frontal sinuses or for patients who have failed previous obliteration.
The definition of success in Draf III procedures is not straightforward: When used for the removal of tumours, complete tumour removal is probably the benchmark. In patients however with CRS, symptom resolution as well as patency of the frontal sinus drainage pathway are both valid indicators of a successful outcome. However, one may notice that although the endoscopic success rate of $85 \%$ patent ostia at follow up is very close to the clinical success rate of $88 \%$, it does not refer to the same patients: ten out of the total of 103 patients with open ostium had persistent symptoms, while on the other hand, 3 out of 12 patients with completely obstructed ostium were asymptomatic. This highlights the limitations of our current methodology in correlating patients' symptoms with their disease, and is one of the most pressing issues necessitating further research. It is also interesting to note that Weber and Draf in their series of patients with frontal sinus surgery showed a discrepancy between $85 \%$ endoscopic and $91 \%$ clinical success rates ${ }^{(3)}$. Other studies, that have assessed facial pain in sinusitis, show that between $56-77 \%$ of patients who have facial pain are better after sinus surgery ${ }^{(6-8)}$. The $45-23 \%$ non-responder group is heterogeneous: It includes patients with non-sinusogenic pain as well as patients with CRS-induced headache where surgery was not effective. We feel that our non-responders belong to both of these groups. Although we used the EPOS criteria (9) for identifying and selecting patients for surgery, our patients were a highly selected group who had undergone multiple surgeries in the past, and thus had a higher risk of postoperative neuropathic pain - which can be as high as $46 \%$ in patients having undergone a Caldwell-Luc procedure ${ }^{(10)}$. Equally, we used the criterion of open neo-ostium to define surgical success.

Table 1. Risk of neo-ostium stenosis

\begin{tabular}{|c|c|c|c|c|}
\hline & & Open Ostium & Closed Ostium & p-value \\
\hline $\begin{array}{l}\text { Age: } \\
\text { Mean (SD) }\end{array}$ & & $47.2(13.1)$ & $51.7(15.5)$ & 0.27 \\
\hline \multirow[t]{2}{*}{ Gender: $\%, \mathrm{n}$} & Male & $91 \%(49)$ & $9 \%(5)$ & 0.72 \\
\hline & Female & $89 \%(53)$ & $11 \%(6)$ & \\
\hline $\begin{array}{l}\text { Previous surgeries: } \\
\text { Mean (SD) }\end{array}$ & & $3.4(3.3)$ & $3.5(2.8)$ & 0.94 \\
\hline \multirow[t]{2}{*}{ Allergy: \% (n) } & Present & $81 \%(25)$ & $19 \%(6)$ & 0.04 \\
\hline & Absent & $94 \%(77)$ & $6 \%(5)$ & \\
\hline \multirow[t]{2}{*}{ ASA triad: $\%$ (n) } & Present & $80 \%(12)$ & $20 \%(3)$ & 0.13 \\
\hline & Absent & $92 \%(89)$ & $8 \%(8)$ & \\
\hline \multirow[t]{2}{*}{ Asthma: \% (n) } & Present & $84 \%(37)$ & $16 \%(7)$ & 0.07 \\
\hline & Absent & $94 \%(65)$ & $6 \%(4)$ & \\
\hline \multirow[t]{2}{*}{ Smoking: \% (n) } & Yes & $94 \%(16)$ & $6 \%(1)$ & 0.48 \\
\hline & No & $90 \%(86)$ & $10 \%(10)$ & \\
\hline $\begin{array}{l}\text { AP diameter } \\
\text { Mean, } \mathrm{SD}\end{array}$ & & $14.3(2.2)$ & $14.0(2.4)$ & 0.64 \\
\hline $\begin{array}{l}\text { Lateral diameter } \\
\text { Mean, SD }\end{array}$ & & $25.5(3.1)$ & $24.5(3.7)$ & 0.35 \\
\hline $\begin{array}{l}\text { L-M score } \\
\text { Mean, SD }\end{array}$ & & $13.3(6.2)$ & $16.0(6.7)$ & 0.18 \\
\hline
\end{tabular}


Table 2. Neo-Ostium stenosis by indication.

\begin{tabular}{|c|c|c|c|c|}
\hline & & \multicolumn{2}{|c|}{ Ostium Status } & \multirow[b]{3}{*}{ Total } \\
\hline & & & $\begin{array}{l}\text { Partly or } \\
\text { completely }\end{array}$ & \\
\hline & & Closed & Open & \\
\hline \multirow[t]{12}{*}{ Indication } & \multirow[t]{2}{*}{$\mathrm{CF}$} & 2 & 3 & 5 \\
\hline & & $40.0 \%$ & $60.0 \%$ & $100.0 \%$ \\
\hline & \multirow[t]{2}{*}{ CRS } & 1 & 21 & 22 \\
\hline & & $4.3 \%$ & $95.7 \%$ & $100.0 \%$ \\
\hline & \multirow{2}{*}{$\begin{array}{l}\text { Inverted } \\
\text { Papilloma }\end{array}$} & 1 & 4 & 5 \\
\hline & & $20.0 \%$ & $80.0 \%$ & $100.0 \%$ \\
\hline & \multirow[t]{2}{*}{ Mucocoele } & 1 & 17 & 18 \\
\hline & & $5.6 \%$ & $94.4 \%$ & $100.0 \%$ \\
\hline & \multirow[t]{2}{*}{$\mathrm{NP}$} & 5 & 53 & 58 \\
\hline & & $10.2 \%$ & $89.8 \%$ & $100.0 \%$ \\
\hline & \multirow[t]{2}{*}{ Osteoma } & 1 & 4 & 5 \\
\hline & & $16.7 \%$ & $83.3 \%$ & $100.0 \%$ \\
\hline \multirow{2}{*}{\multicolumn{2}{|c|}{ Total }} & 11 & 102 & 113 \\
\hline & & $9.7 \%$ & $90.3 \%$ & $100.0 \%$ \\
\hline
\end{tabular}

However, the sinusogenic pain in frontal sinusitis may, in addition to the pressure component, also have a mucosal, inflammatory component that may persist as the frontal sinus mucosa continues to be inflamed despite the creation of an open drainage pathway. And of course we have to admit, in retrospect, that our selection criteria for surgery are still far from accurate, and probably resulted in a number of patients with atypical facial pain undergoing surgery.

From a patient's (and also shareholder's) point of view, perhaps even more important is the rate of revision surgery: our $32 \%$ revision rate may appear high. However, we know from the restrospective case series of patients treated surgically for chronic frontal sinusitis that to judge its results a long follow-up is necessary. Although some maintain that all re-stenosis occurs within the first year ${ }^{(11)}$, others have noticed stenosis up to 26 months after surgery ${ }^{(12)}$. Until now, only a handful of studies have provided medium to long term (> 24 months mean follow up) results for Draf III procedures and only three of them for more than 20 patients: Schlosser ${ }^{(12)}$ looked at 44 patients with 40 months mean follow up and recorded a $32 \%$ revision rate, Samaha et al. ${ }^{(13)}$ at 66 patients after 49 months mean follow up and had 15\% revision rate, while Tran and Wormald ${ }^{(1)}$ with 77 patients followed up for an average 29 months had a $13 \%$ revision rate.

In our study, we found indeed that $64 \%$ (25/39) of our revisions were done within the first 12 months. However, an additional 7 were done in the second year, and patients continued to be operated in the third (3/39) and fourth year (4/39). This emphasizes the need for long-term follow-up and we continue to follow up some of our patients, hopefully to present 10 years results. We consider the assessment for the need for revision surgery a vital part of the follow up and we tend to be proactive in listing patients for revision surgery: With this rationale, patients with limited problems but very narrow neo-ostium
Flowchart 1. Patients operations.

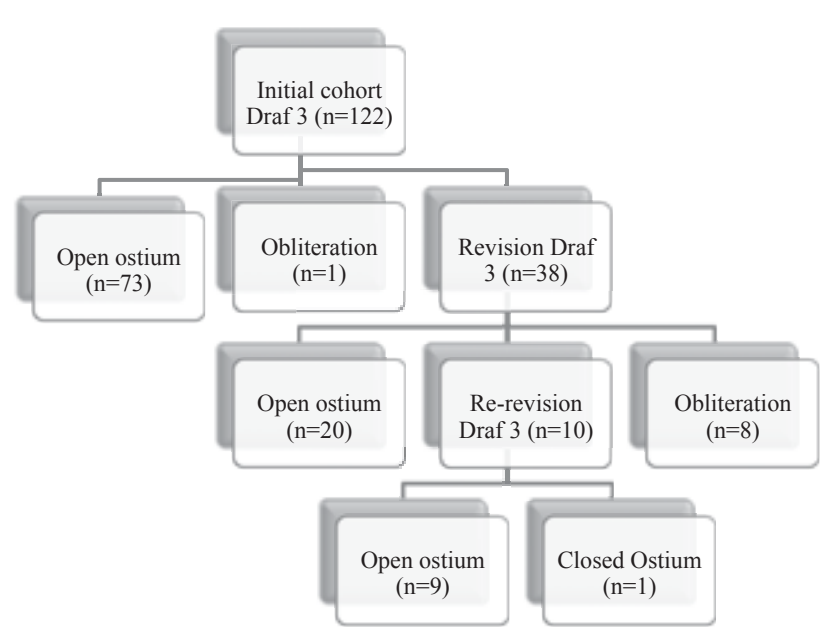

were often listed for revision Draf III, which was often a debridement of scar and granulation tissue, often performed as an outpatient procedure under local anaesthetic.

Our findings of higher stenosis rates for patients with allergy, asthma and ASA triad mirror those by Tran and Wormald ${ }^{(11)}$ who also noticed an association between eosinoplilic mucin CRS and re-stenosis and reflect the more persistent nature of the underlying disease in these patients. Intensive long-term medical and surgical management in these patients is warranted.

Finally, we did not have any serious (intracranial or orbital) complications in our series: We feel that the use of navigation is vital in confirming the surgeon's good anatomical knowledge (rather than supplementing it), and its use contributed to the above. The wealth of accumulated single - centre experience in this procedure undoubtedly also played a role in smoothening the learning curve.

\section{CONCLUSION}

Draf III or EMLP procedure is a safe and effective procedure for patients who have failed conventional frontal sinus procedures and a valid alternative to frontal sinus obliteration. Although the revision rate may appear to be quite significant, revision can often be performed as an outpatient procedure and needs to be balanced against the reduced morbidity and the ease of follow-up.

\section{REFERENCES}

1. Hardy JM, Montgomery WW. Osteoplastic frontal sinusotomy: an analysis of 250 operations. Ann Otol Rhinol Laryngol. 1976; 85: 523-532.

2. Draf W. Endonasal micro-endoscopic frontal sinus surgery: The Fulda concept. Op Tech Otolaryngol Head Neck Surg. 1991; 2: 234-240.

3. Lund VJ, Mackay IS. Staging in rhinosinusitus. Rhinology. 1993; 31: 183-184. 
4. Piccirillo JF, Edwards D, Haiduk A, Yonan C, Thawley SE. Psychometric and clinimetric validity of the 31-item rhinosinusitis outcome measure (RSOM-31). Am J Rhinol. 1995; 9: 297-306.

5. Weber R, Draf W, et al. Modern concepts of frontal sinus surgery. Laryngoscope. 2001; 111: 211-216.

6. Levine HL. Functional endoscopic sinus surgery: evaluation, surgery, and follow-up of 250 patients. Laryngoscope. 1990; 100: 79-84.

7. Jajobsen J, Svendstrup F. Functional endoscopic sinus surgery in chronic sinusitis - a series of 237 consecutively operated patients. Acta Otolaryngol. 2000; Supplement 543: 158-161.

8. Sobol SE, Wright ED, Frenkiel S. One-year outcome analysis of functional endoscopic sinus surgery for chronic sinusitis. J Otolaryngol. 1998; 27: 252-257.

9. Fokkens W, Lund V, Mullol J, European Position Paper on Rhinosinusitis and Nasal Polyps group. European position paper on rhinosinusitis and nasal polyps 2007. Rhinol Suppl. 2007: 1-136.

10. Low WK. Complications of Caldwell-Luc operation and how to avoid them. Aust NZ J Surg. 1995; 65: 582-585.
11. Tran KN, Beule AG, Singal D, Wormald PJ. Frontal ostium restenosis after the endoscopic modified Lothrop procedure. Laryngoscope. 2007; 117: 1457-1462.

12. Schlosser RJ, Zachmann G, Harrison S, Gross CW. The endoscopic modified Lothrop: long-term follow-up on 44 patients. Am J Rhinol. 2002; 16: 103-108.

13. Samaha M, Cosenza MJ, Metson R. Endoscopic frontal sinus drillout in 100 patients. Arch Otolaryngol Head Neck Surg. 2003; 129: 854-858.

\section{Georgalas}

Department of Otorhinolaryngology

Academic Medical Center (AMC)

Meibergdreef 9

1105 AZ Amsterdam

The Netherlands

E-mail: c.georgalas@amc.nl

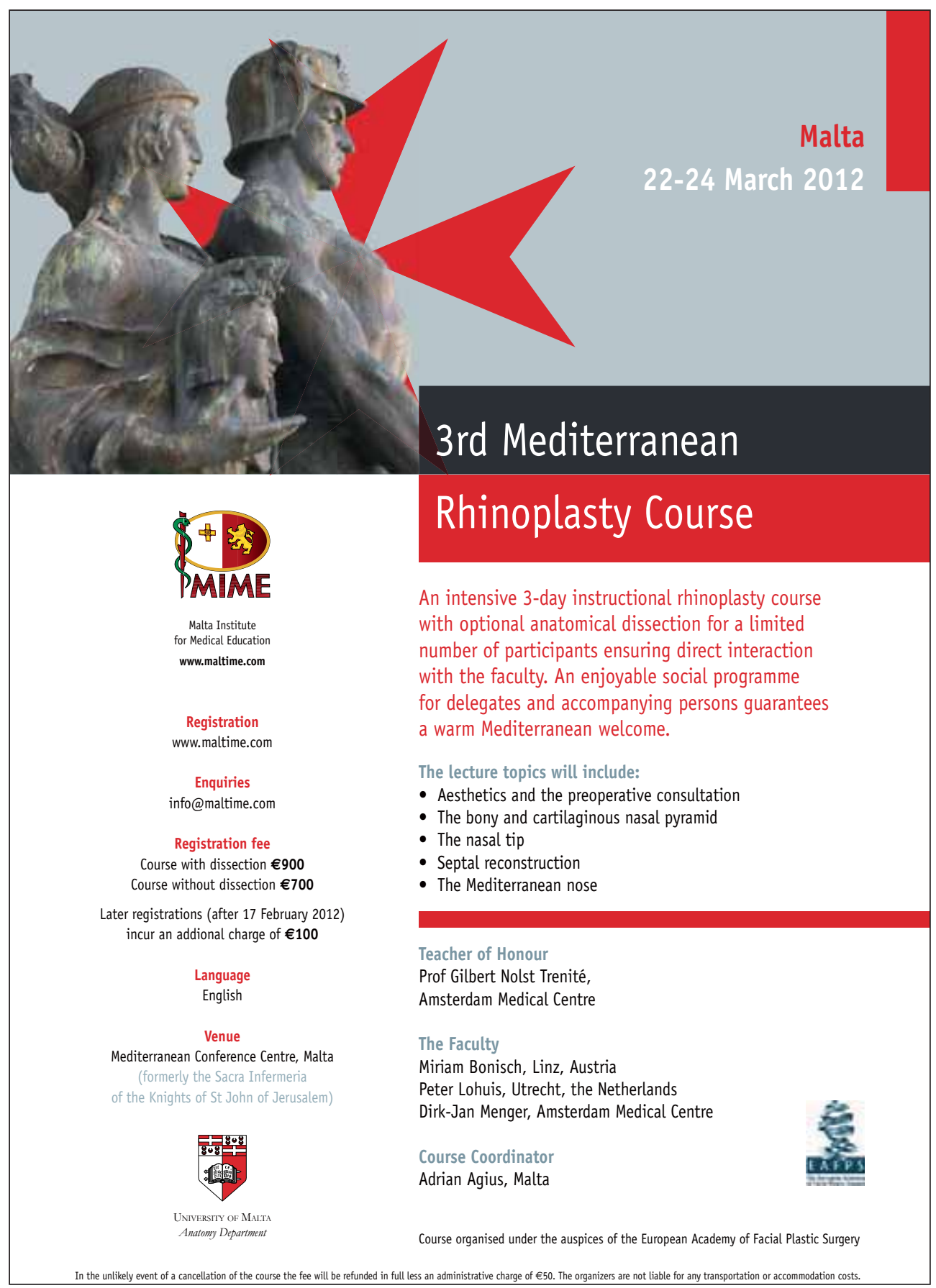

